\title{
Papel do Estado para o desenvolvimento do SNI: lições das economias avançadas e de industrialização recente * Ester Carneiro do Couto Santos *
}

\begin{abstract}
Resumo
O presente trabalho visa apresentar empiricamente a atuação do Estado para a promoção do Sistema Nacional de Inovação (SNI) em países desenvolvidos e países de industrialização recente. Para tanto, analisa algumas de suas ações na Alemanha, Japão, EUA, Taiwan e Coreia do Sul tanto nos estágios iniciais de seu processo de mudança técnica quanto para a manutenção da posição alcançada, procurando fornecer um painel resumido do papel do Estado para o desenvolvimento tecnológico. Em linhas gerais observou-se que a atuação desse agente, longe de ser neutra, mostra-se de fundamental importância para o alcance de uma trajetória tecnológica nacional superior nestas economias.
\end{abstract}

Palavras-chave: Estado; Políticas públicas; Mudança técnica; Sistema Nacional de Inovação; Capacidade tecnológica nacional.

\section{Abstract \\ Role of the State in the development of the NSI: lessons from advanced and recently industrialized economies}

The aim of this paper is to empirically present the operation of the state in the promotion of the National System of Innovation (NSI) in developed and recently industrialized countries. In order to do so, some of its main activities in Germany, Japan, USA, Taiwan and South Korea in the early stages of the process of technical change are examined, in order to provide a summarized framework of the role of the state regarding technological development. In general, it was observed that the activity of this agent is not neutral, but is fundamentally important in achieving a higher national technological trajectory in these economies.

Keywords: State; Politics; Technical change; National Systems of Innovation; Indigenous technological capacity.

JEL O30, O31, O33.

\section{Introdução}

Pelo menos desde Solow (1957), reconhece-se a importância da tecnologia para o crescimento econômico nos chamados modelos neoclássicos de crescimento. A tecnologia, quando inserida dentro de uma função de produção, parece ter a capacidade de elevar a produtividade dos fatores (Nelson, 1996). Contudo, uma simples transferência tecnológica de uma localidade a outra, sem uma

\footnotetext{
* Trabalho recebido em 21 de novembro de 2011 e aprovado em 8 de maio de 2013.

** Pesquisadora em Ciência e Tecnologia na Fundação João Pinheiro (Jㅏ), Belo Horizonte, MG, Brasil. E-mail: estercarneirobr@gmail.com.
} 
correspondente internalização da capacidade de aprendizagem, não é possível realizar efetivamente um avanço tecnológico (Santos, 2014).

Para que uma nação possa promover a mudança de sua base tecnológica, é necessária a absorção de uma ampla base de conhecimentos que possam ser inseridos em sua base produtiva. Como destaca Amsden (2001), em tese, a transferência de tecnologia deveria capacitar o comprador a executar as normas mundiais de produtividade, porém, como a tecnologia é subentendida, ou nunca plenamente codificável, nunca é alcançada uma paridade produtiva entre comprador e vendedor. Nesse sentido, é necessário um esforço de aprendizagem nacional para que as partes não codificáveis possam ser compreendidas.

Não obstante, existe um grande diferencial entre o esforço em nível da firma individual e esforço coletivo, sendo este último mais do que a mera soma dos esforços individuais. Conforme destaca Lall (2000, p. 26), a capacidade tecnológica nacional "abrange o sistema extra mercado das redes e vínculos entre empresas, os estilos de fazer negócios, bem como a rede de instituições de apoio", sendo que estes aspectos afetam substancialmente a maneira pela qual as empresas interagem entre si e a eficácia na troca de informações necessárias para coordenação de suas atividades a fim de se beneficiarem do aprendizado coletivo.

O Sistema Nacional de Inovações (SNI), em linhas gerais, representa o conjunto de fatores nacionais que propiciam ou inibem o florescimento dessas capacidades inovativas nos países. Este compreende o "conjunto de instituições, cujas interações têm papel determinante no desempenho da inovação" como instituições educacionais, financeiras, empresas, universidades, governo, etc. (Nelson; Rosenberg, 1993, p. 3). Alternativamente, Lundvall (1992, p. 2) amplia este conceito incluindo não apenas as instituições, mas também os "elementos e relações que interagem na produção, difusão e uso do conhecimento novo e economicamente útil (...) que estão enraizados dentro das fronteiras nacionais".

Assim, todos os elementos que contribuem para a formação de um ambiente nacional que favoreça/iniba a atividade inovadora são tomados em consideração, estando incluídos não apenas universidades, sistema financeiro e Estado, etc., mas também cultura empresarial, capital social, condições do mercado de trabalho, regulação macroeconômica, etc. O SNI de uma nação, nesse sentido, é entendido como um conjunto amplo e sistêmico de fatores e engloba relacionamentos entre e dentre as organizações, instituições e estruturas socioeconômicas. Tais fatores determinam a taxa e direção da inovação e construção de competências que emanam dos processos de aprendizagem baseados na ciência e na experiência. Nesse sentido, por esta visão, medidas similares podem não surtir o mesmo efeito, ou não promover a convergência no desempenho das nações (Lundvall et al., 2009). 
Mesmo tomando em conta esta concepção mais ampla, o papel do Estado possui papel de destaque para a construção do SNI por possuir capacidade de interferir desde aspectos mais tangíveis, como a promoção e coordenação direta de políticas para o seu desenvolvimento de longo prazo, como a regulação macroeconômica e do sistema financeiro, políticas de educação e treinamento, investimentos diretos em $\mathrm{P} \& \mathrm{D}$, até aspectos menos palpáveis como fortalecimento do capital social, e adoção de políticas que promovam a mudança no comportamento das firmas (Mowery; Rosenberg, 1998; Amsdem, 2007; Nelson, 1993).

O Estado, ao longo da história, tem se apresentado como ator central para o desenvolvimento das habilidades nacionais, pois tem possibilidade de interferir em quase todos os ambientes da vida econômica, tendo escala para promoção desde um grande conjunto de medidas estratégicas para o florescimento de novas habilidades produtivas entre as empresas, até para o financiamento direto de atividades inovativas. A fim de realizarem o catch up, historicamente, as nações fizeram usos recorrentes de políticas de apoio estatal para promoção deliberada de avanço científico e tecnológico. Nesse sentido, os governos adotam posturas mais agressivas quando partem para uma mudança técnica de cunho mais radical (ingresso em novos paradigmas tecnoeconômicos [Freeman, 1991]); e mesmo após alcançarem a posição desejada, com um setor produtivo mais fortalecido, o Estado continua atuando, ainda que indiretamente (Nelson, 1993).

Não apenas em nações subdesenvolvidas, como principalmente nas desenvolvidas, o papel do Estado para indução da competitividade empresarial, por meio da atuação em diversas frentes, tem se mostrado de singular importância, especialmente nos estágios iniciais de desenvolvimento dos SNIs. (Amsden, 2001; Freeman, 1995; Lundvall et al., 2009). Para o caso dos países desenvolvidos, longe de se manter neutro, o Estado tem atuado incisivamente para a promoção da mudança técnica em suas estruturas produtivas. Isto porque os livres mercados podem levar a subinvestimentos em tecnologias complexas, em função de seus custos elevados, altos riscos, longos períodos de aprendizado e externalidades muito difusas (Lall, 2000; Freeman, 1987).

A atuação do Estado tem mudado ligeiramente apenas em função do paradigma tecnoeconômico vigente à época de realização do catch $u p^{1}$, das características da sociedade e do momento histórico específico. Porém, o conjunto de políticas não parece ter mudado substancialmente. Nos estágios iniciais de desenvolvimento tecnológico, tem-se verificado por meio de estudos empíricos, que nações desenvolvidas e subdesenvolvidas têm lançado mão de um conjunto

(1) Catch up, neste trabalho, é entendido como catch up tecnológico. 
similar de políticas para a realização do catch up, ou de condições tecnológicas superiores (Freeman, 1984, 1995; Lall, 2000; Nelson, 1993).

Já quando se comparam políticas aplicadas durante as fases iniciais de desenvolvimento do SNI de nações que realizaram o catch up em paradigmas tecnoeconômicos distintos, verifica-se que, para aquelas que o fizeram posteriormente é necessário um conjunto mais intenso de medidas simultâneas e em velocidade superior aos países com SNIs maduros, visando redução de gaps tecnológicos (Albuquerque, 2009, Wade, 1990).

As ações engendradas pelo Estado alemão em meados do século XVII para fortalecimento de seu SNI e realização de seu catch up em relação à Inglaterra e EUA, já não são mais suficientes (embora sejam necessárias) para países asiáticos de industrialização que passaram por este momento na segunda metade do século XX (Amsden, 2007). Isto por que a cada revolução tecnológica, combinam-se novas e antigas tecnologias para a construção de um novo paradigma, ampliando os requerimentos mínimos ao ingresso de um novo ator nesse paradigma tendo em vista a questão da cumulatividade envolvida no processo (Perez, 2002).

Com o passar do tempo, após o alcance do patamar de desenvolvimento tecnológico almejado, as economias passam a possuir outros tipos de políticas para garantir sua permanência dentro do jogo que continua em andamento. Nesse sentido, as ferramentas mudam, mas o papel do Estado continua presente (Ergas, 1987).

Este trabalho objetiva, nesse sentido, sistematizar algumas ações do Estado na formação e promoção dos SNIs, para o alcançamento do catch up e manutenção de suas posições atingidas em três economias avançadas e duas de industrialização recente, respectivamente, Alemanha, Japão, EUA, Taiwan e Coreia do Sul. O trabalho está dividido em três sessões além desta introdução. Na primeira, encontra-se a discussão voltada aos países desenvolvidos - Alemanha, Japão e EUA -, na segunda, a discussão sobre os países de industrialização recente Taiwan e Coreia do Sul, e, por fim, na última, as conclusões.

\section{Países desenvolvidos}

\subsection{Alemanha}

O principal esforço do Estado alemão no sentido de fortalecer seu SNI centra-se no desenvolvimento de um sistema educacional competitivo. A educação superior alemã desde o século XVIII tem se mostrado um ponto fundamental para seu diferencial, sendo composta por uma base complexa de redes e níveis. Segundo Keck (1993), as primeiras universidades alemãs surgiram no século XVIII, sendo seguidas pelas escolas politécnicas criadas no início do século XIX (que foram elevadas a nível superior em 1860), pela criação de escolas de nível médio técnico 
no mesmo período e pela criação das escolas de negócio no início do século XX a fim de propiciar uma melhor definição das técnicas de gerenciamento empresariais. Já no século XVIII, a Alemanha já apresentava educação básica para todos com idade entre 6 e 13, portanto, antes da revolução industrial.

Juntamente com as ações no âmbito da educação, o governo prussiano promoveu e coordenou medidas de transferência de tecnologia. Conforme aponta Freeman (1995), o Estado criou o os Institutos de Treinamento Técnico e garantiu que haveria importação de máquinas inglesas para engenharia reversa e treinamento de artesãos alemães para que fossem disseminadas as novas tecnologias na indústria nacional. Também buscou atrair para a Prússia operários ingleses objetivando adquirir o conhecimento tácito necessário à operação das máquinas adquiridas.

Por volta de 1840, Landes (1970) aponta que o governo enviava oficiais alemães aos EUA em 'viagens de inspeção' provendo-lhes todos os recursos necessários, além de financiar estudantes por longos períodos neste país. O governo provia ainda consultoria, assistência técnica e subvenções a inventores e empreendedores imigrantes concedendo isenções de impostos para a importação de equipamentos industriais (Freeman, 1995).

Não obstante, a falta de unificação nacional não permitia que os benefícios oriundos desses esforços fossem aproveitados em sua plena capacidade. Com a unificação política alemã em 1871, o país passou a experimentar substanciais ganhos de eficiência em seu desenvolvimento tecnológico e científico. Estes ganhos também já começariam a se tornar visíveis desde 1815 com as guerras napoleônicas e congresso de Viena, com a redução do número de províncias alemãs.

As barreiras alfandegárias, de costumes, leis, etc., foram sendo progressivamente eliminadas e outras infraestruturas físicas de uso coletivo como estradas, portos e ferrovias foram construídas, facilitando a circulação de mercadorias. Os fundos governamentais para a educação superior e pesquisa científica cresceram entre 1860 e 1913, a uma taxa média de $9 \%$ ao ano em termos reais, permitindo que o número de estudantes matriculados em nível superior mais que quadruplicasse no mesmo período. No início do século $\mathrm{XX}$, o sistema educacional alemão apresentava uma estrutura complexa e sofisticada perpassando desde o nível elementar até ao nível de doutorado, sendo que o governo era responsável por mais da metade de seus gastos (Keck, 1993).

A unificação propiciou o entendimento de desenvolvimento nacional e o Estado realizou esforços no sentido de promover o catch up industrial alemão que à época estava em atraso perante os demais países europeus. Nesse sentido, o Estado passou a oferecer suporte financeiro direto para as importações de maquinários que 
foram sendo incorporados às plantas nacionais. Ademais, o governo também passou a oferecer subsídios para que os alemães pudessem visitar empresas britânicas e belgas, inclusive para a realização de espionagem industrial.

$\mathrm{Na}$ Alemanha as empresas privadas sempre tiveram um papel bastante ativo na consolidação do desenvolvimento tecnológico, inclusive na criação de cursos técnicos e até alguns superiores. Porém, o papel do Estado foi decisivo para incrementar a ação do setor privado, principalmente no tocante ao financiamento do sistema educacional, permitindo uma maior fluidez na formação de novos profissionais e ampliação no avanço da ciência. Entre 1860 e 1910, os fundos governamentais somente para universidades cresceram a uma taxa de 5\% ao ano em termos reais. E o setor privado pôde beneficiar-se desse investimento. Já em 1897 havia cerca de 3.000 químicos empregados na indústria alemã. Ademais, a tutela governamental nesse período também se fez mostrar em termos de governança, de modo que o Estado acompanhava e supervisionava de modo estreito as universidades. Este fato é verificado, por exemplo, na atuação direta do oficial sênior do ministério da cultura Fredrich Altof, que atuou no período de 1882 a 1907 na escolha direta dos melhores professores em suas áreas, para atuação nas universidades alemãs (Keck, 1993).

Com a coordenação de esforços entre os setores governamental e privado, também foi possível a criação de laboratórios de pesquisa em áreas de interesse industrial. Em 1874 foi criado o primeiro laboratório de pesquisa em uma associação entre o governo e a indústria em caráter experimental na área agrícola, onde o primeiro entrou com área física construída e a segunda com os custos operacionais e equipamentos. Mas o principal instituto de pesquisa colaborativo foi estabelecido entre o industrial Werner Von Siemens e o governo, para o desenvolvimento de instrumentos de precisão, criado em 1887, denominado Instituto Imperial de Física e Tecnologia, onde o governo teve mais intensa participação financeira. Tal união auxiliou a consolidação da empresa Siemens como importante player global (Cahan, 1985).

Em 1914 já havia quatro institutos de pesquisa constituídos na Alemanha em um formato que hoje poderíamos chamar de parceria público-privada nas áreas de química, físico-química, mineralogia e biologia, além dos 50 laboratórios públicos existentes. Assim, novos arranjos institucionais e a presença forte do Estado permitiram ganhos de eficiência ao sistema econômico alemão para o desenvolvimento do progresso tecnológico.

No pós-guerra, as perdas alemãs foram sendo progressivamente restauradas por meio dos investimentos pretéritos nacionais em educação e ciência. Não obstante, o investimento em pesquisa científica passou a ser liderado pelas 
Papel do Estado para o desenvolvimento do SNI: lições das economias avançadas...

empresas. Os fundos governamentais para essa finalidade se escassearam devido à crise econômica do país, aliada a sua crise política e social do imediato pós-guerra.

O papel do governo passou a estar mais vinculado à questão da governança. Segundo Guimarães (2006), grande parte da recuperação do país no pós-guerra esteve ligada ao seu arranjo institucional de regulação via networks (entre associações de trabalhadores, empresários, Estado, bancos) em que o Estado possuiu papel de coordenação. Nesse sentido, o Estado apresentou papel de destaque nessa coordenação sistêmica dos atores envolvidos no processo de mudança econômica. Como exemplo, nesse período, o governo passou a interferir nas relações de trocas de tecnologia entre universidades e empresas, por meio da criação de escritórios com essa finalidade nas universidades, além de conceber novos programas para fortalecer a cooperação entre as firmas ou entre firmas e institutos públicos de pesquisa (Ergas, 1987).

Políticas de subsídio também foram adotadas objetivando aumentar a competitividade da indústria nacional. Em meados da década de 1980, o Ministério Federal de Economia passou a fornecer um subsídio parcial para o emprego de engenheiros e cientistas para atividades de pesquisa em pequenas e médias empresas. Também passou a oferecer subsídios para empresas de áreas selecionadas (como microeletrônica, biotecnologia e robótica), para que estas participassem de projetos cooperativos e aumentassem seus gastos com P\&D (Ergas, 1987).

Já em meados na década de 1990, mesmo no auge no neoliberalismo, viuse a necessidade de implementação de um arranjo institucional específico bem como um suporte financeiro adequado para o fomento do desenvolvimento tecnológico e científico, a partir da verificação da queda dos gastos do setor privado em P\&D. Assim, o governo funde o Ministério da Educação e Ciência e o Ministério da Pesquisa e Tecnologia em um novo Ministério Federal de Educação, Ciência, Pesquisa e Tecnologia, buscando uma maior coordenação entre as áreas, além de um provimento mais adequado de recursos. Ademais, o envolvimento governamental nas políticas tecnológicas passou a estar centrado na redução de impostos a produtos tecnológicos e no fornecimento de incentivos ao capital de risco, passando a ampliar os incentivos fiscais ao invés dos incentivos diretos (Matesco; Hansenclever, 1996), além da oferta de infraestrutura educacional.

Em suma, o que se depreende da breve análise do papel do Estado para o desenvolvimento de um Sistema Nacional de Inovações alemão é sua forte participação institucional na coordenação de forças em torno de um objetivo nacional. Por outro lado, o forte investimento pretérito em educação e ciência formou as bases da construção de seu SNI. 


\subsection{Japão}

A história de formação de SNI japonês inicia-se com a presença de um forte investimento em educação. Desde a era Tokugawa (1603-1868) - governo feudal - o nível de educação básica japonês era muito elevado. Havia educação compulsória para todos os filhos dos samurais, sendo que os níveis educacionais eram maiores que em qualquer outro país europeu à época (Odagiri; Goto, 1993).

Com o inicio da era Meiji (após 1868), que representou a centralização do Estado japonês, houve um esforço coordenado das autoridades japonesas para a implementação da universalização do ensino básico. Apenas para se ter uma ideia, em 1904, quando a educação compulsória foi finalmente estabelecida, a taxa média de cobertura educacional básica (6 anos de educação) era de $99 \%$ para meninos e $96 \%$ para meninas; dados superiores à educação básica brasileira, mais de um século depois (Odagiri; Goto, 1993).

A industrialização japonesa foi tecnologicamente avançada, e o Estado primeiramente exerceu esforços de sistematização de investimentos em novas tecnologias, transferindo-as depois ao setor privado. Essas novas tecnologias eram trazidas por profissionais do exterior, principalmente da Alemanha e França, mas foram sendo progressivamente implementadas no sistema produtivo japonês por meio de adaptações feitas pelos profissionais japoneses especializados. Nesse ponto, o governo também atuou ao realizar altos investimentos na formação de mão de obra que seria posteriormente utilizada pelas firmas. Isto porque havia o entendimento da necessidade de internalização e aprendizagem das tecnologias estrangeiras, e esta não seria possível sem a presença de profissionais capazes de aprender, modificar e criar novas tecnologias adequadas ao cenário nacional japonês ${ }^{2}$. Assim o progresso tecnológico da indústria japonesa vinha de fora e de dentro do país (Freeman, 1987).

Esses investimentos inicialmente foram engendrados pelo envio de japoneses para universidades do exterior e aproveitamento posterior de suas habilidades por meio do efeito multiplicador promovido pelo ensino aos compatriotas, além da contratação direta de profissionais estrangeiros tanto para atuação na indústria como para o ensino superior, importação de maquinário avançado (e engenharia reversa), licenciamento de tecnologia e investimento direto estrangeiro (IDE). Adicionalmente, nesse período, o governo encorajou os empresários a assimilar tecnologia estrangeira e aplicá-las nas fábricas japonesas (Freeman, 1987).

(2) Odagiri; Goto (1993), por exemplo, relatam que sem a internalização de conhecimentos por parte dos japoneses não teria sido possível a adaptação da tecnologia de mineração da Alemanha para o Japão, que possui características ambientais muito diferentes. 
Em outra frente, no início da era Meiji (em particular nas décadas de 1870 e 1880), o Estado criou empresas públicas em áreas estratégicas, como estradas, construção naval, máquinas e indústria têxtil, em virtude dos altos riscos envolvidos e da baixa capacidade de financiamento do setor privado. Estas acabaram sofrendo falências e foram vendidas ao setor privado posteriormente, porém levavam consigo tecnologias estrangeiras na forma de máquinas, equipamentos e mão de obra treinada que eram transferidas aos empresários nacionais, possibilitando-os ingressarem em novas trajetórias tecnológicas, com custos e riscos menores (Odagiri; Goto, 1993).

O setor militar também foi uma importante base tecnológica ao construir plantas industriais em setores como aço, telecomunicações, munições e indústria aeronáutica na defesa contra a Rússia, que havia acabado de colonizar a China. O governo determinou a realização de um catch up militar com fortes incentivos tecnológicos. Não obstante, a tecnologia desenvolvida pelos militares, bem como a mão de obra empregada, também foi transferida ao setor privado por meio de um esforço de difusão de tecnologia engendrado pelo governo.

O Estado, portanto, passou a atuar em diversas frentes para promoção do catch up industrial. Como exemplo da atuação governamental para o fomento da atividade industrial, Amsden (2001) cita o caso do setor japonês de seda em fins do século XIX. Com a introdução da praga do bicho da seda na produção mundial, a qualidade do produto começou a cair. A fim de tornar o setor mais competitivo, o governo Meiji (i) passou a fiscalizar ${ }^{3}$ o controle de qualidade dos ovos do bicho da seda, além de (ii) criar estações de pesquisa para o estudo de doenças do bicho da seda, (iii) construir fábricas modelo para fiação da seda, que apesar de falirem posteriormente garantiram uma considerável transferência de tecnologia ao setor privado e (iv) oferecer suporte financeiro por meio dos bancos de desenvolvimento nacionais. Como resultado dessas medidas, o Japão passou a ter produtos de melhor qualidade e com um processo produtivo menos custoso que os demais países. Assim, a participação das exportações japonesas de seda no mercado mundial saltou de $6,7 \%$ no período $1859-61$, para $67,2 \%$ no período $1911-13$ e para $83,1 \%$ em 1936-38.

Até o início do século XX o Japão já possuía um setor industrial bem diversificado, porém muito dependente de tecnologias estrangeiras, cujos canais principais se davam por meio da importação de máquinas (e engenharia reversa), licenciamento tecnológico e IDE. Não havia no país uma tradição de desenvolvimento de novas tecnologias por meio da P\&D, nem mesmo uma base

(3) A fiscalização incisiva da qualidade japonesa dos ovos promoveu ampla diferenciação de países como a China, que ao deixar o sistema aos mecanismos de mercado, permitiu que medidas especulativas de curto prazo gerassem uma queda generalizada da qualidade dos ovos. 
científica forte. Porém, utilizando-se de tecnologia desenvolvida no exterior e com uma mão de obra altamente qualificada capaz de utilizá-la, reproduzi-la e adaptála, a participação do setor de máquinas no PIB japonês saltou de $0,7 \%$ em 1875 para $27,6 \%$, em 1940 , enquanto o setor de alimentos decresceu de $61,6 \%$ do PIB para 13\% no mesmo período. Assim, a indústria japonesa decolou durante a primeira guerra e no período entre guerras aumentando consideravelmente suas exportações (Odagiri; Goto, 1993).

Porém, foi durante a Segunda Guerra com a queda do fluxo de tecnologias externas que o Japão ampliou seus esforços em P\&D. Odagiri e Goto (1993) mostram que o número de organizações científicas (entre públicas e privadas) saltou de 349 em 1930 para 711 organizações privadas e 443 públicas em 1942. No entanto, ainda assim, a interrupção dos fluxos de conhecimento do exterior logrou a ampliação do gap tecnológico entre o Japão e os países ocidentais.

Após destruição promovida pela bomba atômica ao fim Segunda Guerra Mundial, o Japão viu-se colapsado: máquinas e equipamentos destruídos, a produção de alimentos reduzida à metade, índice de produção industrial quase $80 \%$ inferior ao período de boom entre guerras, dentre outros. Nesse sentido, o governo japonês teve um papel de peso na reconstrução do pós-guerra. Suas principais ações foram (i) encorajamento à importação de tecnologia avançada - governo alocou o dinheiro estrangeiro disponível no pós-guerra para indústrias capazes de adotar tecnologia estrangeira; (ii) restrições de importações de modo que as empresas estrangeiras podiam apenas vender sua tecnologia, mas a venda de produtos tecnologicamente avançados era restrita; (iii) restrição à entrada de empresas estrangeiras; (iii) restrição ao IDE e (iv) coleção e difusão de inovações realizadas no exterior passaram a ser centralizadas pelo ministério da indústria japonês (Odagiri; Goto, 1993).

Uma interessante medida japonesa do pós-guerra foi a criação, pelo Estado, das chamadas Associações de Pesquisa (Research Association - RAs) que recebiam cerca da metade dos incentivos japoneses para o desenvolvimento de P\&D. Estas associações funcionaram até o início da década de 1980, promovendo um ambiente de produção de pesquisa compartilhada para ser utilizada entre as empresas japonesas, de modo a evitar o favorecimento de firmas particulares e diminuir os custos de supervisão para utilização do subsídio governamental. No total, foram criadas 87 RAs e suas principais áreas de estudo foram computadores e semicondutores (Odagiri; Goto, 1996).

As RAs foram utilizadas como estratégia de transição e se mostraram ineficientes tanto em termos de produtividade quanto na alocação de estudos entre as empresas, porém eficazes em termos de aprendizagem e mudança de paradigma para as empresas japonesas, lançando as bases para a construção de laboratórios de 
Papel do Estado para o desenvolvimento do SNI: lições das economias avançadas...

P\&D nas firmas. Pouco a pouco as empresas passaram a construir seus próprios laboratórios de pesquisa ou realizar pesquisas por meio de acordos conjuntos entre companhias nacionais. Também foram construindo suas próprias redes para absorção de tecnologia externa de modo que o papel anteriormente desempenhado pelo Ministério da Indústria também foi declinando (Odagiri; Goto, 1996).

Após este esforço coordenado do Estado aliado a outros fatores, a economia japonesa cresceu a uma taxa média de $10 \%$ ao ano entre 1950 e 1970 . Nesta última década a participação do governo por meio de subsídios também cresceu no período, porém, em um nível relativamente inferior ao setor privado (Harayama, 2001). Neste período as firmas japonesas também passaram a investir mais pesadamente em P\&D para se manterem competitivas no mercado mundial (Freeman, 1987). Tendo em consideração o substancial aumento da robustez tecnológica japonesa, Ohkawa e Kohama (1989) afirmam que o catch up tecnológico japonês houvera sido finalizado na década de 1970.

Não obstante, como se observou, a construção deste setor empresarial robusto não se fez também sem o auxilio do governo desde o século XIX, principalmente em relação ao investimento na formação de mão de obra capacitada, compra de tecnologia (principalmente alemã), e contratação de profissionais qualificados tanto para atuação na indústria quanto para o ensino.

\subsection{Estados Unidos}

Os EUA, de formação mais recente - tornados independentes em 1776 -, até a Segunda Guerra Mundial, possuíam capacidade limitada em desenvolver e criar novas tecnologias. Tal fato estaria muito ligado à fraca capacidade do país em suas estruturas científicas. Segundo Cohen (1976), todos os cientistas americanos 'sérios' haviam completado seus estudos em universidades europeias. Não obstante, as empresas faziam seus desenvolvimentos em P\&D internamente, principalmente aplicando e adaptando conhecimentos já existentes criados por países mais avançados cientificamente. (Mowery; Rosenberg, 1998)

A lei antitruste do início do século XX foi uma das primeiras atuações governamentais para a o aumento da concorrência das indústrias americanas. Ao tornar mais difícil a cartelização dos grupos, as estratégias competitivas das empresas passaram a voltar-se mais para a busca de novos de produtos e processos. A regulamentação dos direitos de propriedade, que se tornou mais bem definida e com maior impacto nas duas primeiras décadas do século $\mathrm{XX}$ foi outra política governamental que gerou impacto sobre a busca por novas tecnologias dentro das empresas. Com esta definição, as empresas passaram a realizar mais inovações por meio do estabelecimento de maiores rotinas de busca interna e monitoramento de tecnologias externas. Ademais, o mercado estabelecido por meio dos direitos de 
propriedade no desenvolvimento, licenciamento e compra de patentes permitiu uma fertilização cruzada entre os setores, o que gerou um maior florescimento de novas tecnologias intersetoriais.

O aumento da busca competitiva entre empresas também as levou a estabelecerem laços com as universidades, porém com o objetivo de mapearem e adaptarem as novas tecnologias existentes, uma vez que até 1940, as universidades americanas estavam muito focadas na formação e treinamento, em especial ligados à engenharia e no tocante à pesquisa funcionavam como radares de busca de tecnologias externas. Os gastos federais durante a década de 1930 representaram entre $12 \%$ a $20 \%$ dos gastos totais dos EUA em P\&D apenas, enquanto a indústria foi responsável por dois terços desse total (Mowery; Rosenberg, 1993).

A esta época, os EUA não tinham um significativo avanço tecnológico e científico. Este país atuava principalmente nas adaptações e melhorias dos desenvolvimentos de tecnologias externas. Somente após a Segunda Guerra Mundial, o país deixou de ser seguidor em ciência para se tornar líder e o papel do governo federal foi fundamental para a alavancagem do SNI americano. O Estado passou a atuar de forma coordenada para a promoção de uma trajetória tecnológica superior no país.

Com a Segunda Guerra Mundial e a queda no influxo de tecnologias estrangeiras, os EUA viram-se impelidos a desenvolver novas tecnologias, principalmente voltadas para o esforço de guerra. Assim, o governo Federal passou a investir altas somas em $\mathrm{P} \& \mathrm{D}$, dando maior ênfase no desenvolvimento científico. Os gastos federais em P\&D saltaram de US $\$ 83,2$ milhões em 1940 para US $\$ 1,3$ bilhão em 1945, sendo que os gastos do departamento de defesa saltaram de US $\$ 29,6$ para US\$423,6 milhões no mesmo período (em valores de 1930). Os gastos federais em P\&D foram de tal magnitude que, em 1969, foram superiores à soma dos gastos empreendidos pelo Japão, Alemanha Ocidental, Reino Unido e França para a mesma finalidade: os gastos americanos foram da ordem de US\$ 25,6 bilhões, enquanto a soma dos gastos daqueles países em P\&D foi de US\$11,3 bilhões (Mowery; Rosenberg, 1993).

As universidades americanas passaram a ter um papel de destaque para a destinação dos fundos federais em P\&D. De um valor de aproximadamente US\$ 500 milhões em 1935-1936, a pesquisa universitária teve seus fundos aumentados para mais de US\$2,4 bilhões em 1960 e para US\$ 16,8 bilhões em 1995 (valores em dólares de 1987), considerando investimentos públicos e privados. O apoio centrou-se no aumento da capacidade instalada de instrumentos para realização de pesquisas, contratação de pessoal científico e, no caso da ciência da computação, na compra de computadores para institucionalização da nova tecnologia nas 
universidades, tanto para treinamento e formação de mão de obra quanto para o desenvolvimento de novas tecnologias (Mowery; Rosenberg, 1998).

Ademais, o governo ampliou a demanda por pesquisas em áreas estratégicas e esforçou-se para a criação de um ambiente de maiores trocas entre as universidades e empresas (Mowery; Rosenberg, 1993). No tocante ao último ponto, Mowery e Rosenberg (1998) apontam que o impacto de tais políticas foi ainda amplificado, uma vez que induziram o florescimento mútuo desses setores, de modo que a ciência contribuía para novos desenvolvimentos tecnológicos ao mesmo tempo em que estes contribuíam para o avanço da ciência, como no caso dos estudos da ótica e desenvolvimento do laser.

Por outro lado, além da magnitude dos gastos em P\&D terem sido ampliados, também se mudou a forma de aplicação desses gastos, deixando de serem destinados quase que exclusivamente aos laboratórios públicos de pesquisa com maior proeminência para as pesquisas no setor agrícola e defesa - para serem empregados, em sua maioria, na indústria. Em 1985, 73\% dos fundos federais em $\mathrm{P} \& \mathrm{D}$ foram destinados à industria e somente $12 \%$ dos dispêndios foram executados em laboratórios federais de pesquisa. A ampliação desses gastos estimulou não apenas a realização de pesquisas conjuntas com universidades, mas também o desenvolvimento interno da $\mathrm{P} \& \mathrm{D}$ na indústria. Houve, nesse sentido, um significativo aumento dos empregos em pesquisa industrial: em 1946 havia menos de 50 mil engenheiros e cientistas empregados na indústria, em 1962300 mil e em 1996 quase 800 mil (Mowery; Rosenberg, 1998).

Ademais, cumpre salientar que, a indução governamental para o incentivo à pesquisa não se deu apenas pelo lado da oferta de financiamento à $\mathrm{P} \& \mathrm{D}$, mas por um incentivo real de demanda criado pelas compras militares. E estas estimulavam o desenvolvimento e difusão de tecnologias. A corrida por novos desenvolvimentos tecnológicos, cujas compras de suas mercadorias seriam certas pelo governo, fez surgir diversas novas empresas de base tecnológica. O papel indutor do governo nessa esfera teve dois efeitos principais: (i) estimulou a produção de novas tecnologias (como os semicondutores) reduzindo as incertezas associadas às inovações tecnológicas e (ii) ao estimular e utilizar as novas tecnologias na Defesa, sinalizou ao mercado sua efetividade e viabilidade ampliando, assim, a demanda em âmbito comercial.

Como exemplo, podemos citar a construção do IBM 650 de baixo custo, cujo projeto foi iniciado para uma venda de 50 máquinas ao governo Federal (mais do que todos os computadores existentes à época), com uma projeção total de vendas de 250 máquinas. As vendas totais do exemplar na década de 1950 acabaram sendo de 1800 unidades. Sem esse contrato de compra governamental, o projeto provavelmente não teria sido iniciado. De caráter ainda mais profundo, a 
revolução eletrônica do pós-guerra, atribuída a duas inovações cruciais - transistor e o computador - teve sua exploração estimulada pelas preocupações do Estado com a segurança nacional geradas pela Guerra Fria (Mowery; Rosenberg, 1998).

Outra política governamental que induziu a difusão da tecnologia nascente entre as empresas foi a política da segunda fonte. Quando uma empresa desenvolvia uma nova tecnologia para que sua venda fosse realizada para os militares, era exigida a garantia de uma segunda fonte, ou seja, uma empresa que pudesse vender o mesmo produto com as mesmas características técnicas, no caso de falha no fornecimento do produto acordado. Para garantir a existência da segunda fonte, as empresas tinham que dividir seus desenvolvimentos com outra empresa, para garantir a produção de um produto idêntico ao original, o que promovia a difusão e melhorias da inovação produzida (Mowery; Rosenberg, 1998).

Ainda para garantir uma ampla difusão das tecnologias desenvolvidas, os militares faziam audiências públicas sobre os avanços obtidos, em especial na área da computação, a fim de garantir que novos desenvolvimentos seriam feitos e que seria estabelecida uma infraestrutura adequada. Com esta abertura, o crescimento da informática alcançou níveis significativos de avanço tecnológico no pós-guerra, por meio da busca por inovações em diversas empresas, institutos de pesquisa e universidades.

O Estado, portanto, teve forte participação para a construção do SNI americano, impulsionando, financiando e atuando direta e indiretamente para a promoção da mudança técnica. Nesse sentido, não é possível entender o desenvolvimento em C\&T e P\&D dos EUA sem compreender o importante papel de um esforço governamental coordenado empreendido no pós-guerra para alcançar esta finalidade.

Após 1980, a atuação do governo americano para promoção de SNI não diminuiu. Antes, para a manutenção de sua posição de liderança, o Estado continuou investindo fortemente em sua infraestrutura tecnológica e científica. Lee (1997, p.10) aponta oito medidas tomadas pelo governo entre 1980 e 1993 formuladas por vias legais, dentre estas o Bayle Dole Act - 1980 - que permitiu a concessão da titularidade de invenções a universidades e firmas sem fins lucrativos que realizaram pesquisas com fundos governamentais, permitindo seu licenciamento à industria, demonstrando o firme interesse do governo em manter a competitividade das firmas nacionais.

Como resultado, Narin et al. (1997) apontam os benefícios alcançados pela fertilização cruzada entre os gastos governamentais em ciência para o avanço tecnológico em setores selecionados nos EUA, explicitando que a ciência pública apresentou-se como a força motriz por trás da alta tecnologia nacional. Atualmente, 
a economia americana tornou-se uma das mais competitivas do mundo, alcançando liderança tecnológica em diversos ramos, sendo o país que mais produz artigos científicos no mundo, além de liderar o ranking de patentes mundiais e estar em terceiro lugar em termos dos gastos com $\mathrm{P} \& \mathrm{D}$ em proporção ao PIB no mundo (Banco Mundial).

\section{Países de industrialização recente}

\subsection{Taiwan}

O papel do governo foi central para o catch up implementado por Taiwan. Somente com a presença de um plano nacional com políticas que estimulavam diversas áreas concomitantemente foi possível a construção de uma sólida base competitiva em Taiwan. Segundo Hou e Gee (1993), o desenvolvimento de Taiwan somente foi possível após a Segunda Guerra Mundial com sua desocupação pelo Japão em 1945. O país havia sido colônia japonesa por 51 anos servindo o Japão com matérias primas e produtos agrícolas e seu colonizador não tinha interesse em sua industrialização, apesar de deixar algumas infraestruturas básicas como estradas, eletrificação, saúde pública, desenvolvimentos tecnológicos na área de agricultura, além de educação primária. Como destaca Amsden (2001), quando o Japão deixou a ilha, havia apenas duas usinas de algodão, duas fábricas de juta e uma usina de lã.

Com a derrota japonesa na Segunda Guerra Mundial, Taiwan foi devolvida à China e, em 1949, o país tornou-se sede do governo nacionalista chinês. Nesse período, iniciou-se no país uma migração massiva de chineses (mais 2 milhões de pessoas), trazendo uma massa critica de profissionais como professores, homens de negócio, industriais e oficiais de governo, que representavam a nata da cultura chinesa. Ademais, houve a instalação de empresas públicas, que auxiliaram o desenvolvimento da ainda incipiente indústria privada oferecendo principalmente matérias primas a custos mais baixos.

Em 1950 a base industrial de Taiwan era muito fraca. Sua pauta exportadora era baseada principalmente em açúcar, arroz e bananas, e o PIB per capita por volta de 1960 era muito inferior ao de países da América Latina à época ${ }^{4}$. Porém, já em 1989 seu PIB se tornou superior a muitos daqueles que estavam à sua frente em 1960. O PIB per capita de Taiwan saltou para US\$ 7.558 em 1989 e em 2010 foi para US\$ 18.588. Entre 1979 e 1986, o número de pesquisadores engajados em atividades de C\&T por dez mil habitantes saltou de

(4) Em 1960, o PIB per capita de Taiwan era de US\$164, enquanto no Brasil era cerca de US\$208, na Bolívia R\$167 e no Uruguai US\$490. Já em 2010, Brasil, Bolívia e Argentina, apresentaram um PIB per capita de, respectivamente, US\$10.992, US\$ 1.978 e US\$ 11.74 , enquanto em Taiwan esse valor era de US\$ 18.588 . (Taiwan, 2011; Banco Mundial). 
12,8 para 34,9 e o número de $\mathrm{PhD}$ cresceu a uma taxa de $11 \%$ ao ano. (Taiwan 2011; Banco Mundial).

Inicialmente, o Estado executou uma política de substituição de importações realizada na década de 1950 , que permitiu o florescimento de novos setores industriais e um rápido crescimento econômico. Nesse período houve substancial proteção à indústria local com o objetivo de promover seu desenvolvimento e fortalecimento. Para se ter uma ideia da restrição às importações imposta pelo governo, em 1954, as importações na ilha eram de apenas 3,8\% do total da oferta (Amsden, 2001).

Com o sucesso da política verificado pelo substancial aumento da produção, já em fins de 1950 e início de 1960, o mercado interno não era mais capaz de suportar a produção nacional e o governo passou a adotar uma política de expansão da atividade exportadora. Tal política não apenas revitalizou, como modificou a estrutura econômica de Taiwan mudando a vocação do país de agrícola para industrial ${ }^{5}$. Em seguida, o Estado se imbuiu da tarefa de tornar o país uma nação competitiva e, para alcançar tal objetivo, tomou diversas medidas de caráter nacional por meio de um plano de ação conjunta (Wade, 1990).

A atuação do Estado se deu por meio de uma ação estratégica através de políticas em setores selecionados e setores fundamentais. Assim, tomou medidas coordenadas adotando fortes políticas nas áreas de educação, criação de institutos de pesquisa e suporte ao desenvolvimento de indústrias high-tech, políticas para o estabelecimento de alianças tecnológicas com parceiros estrangeiros para o desenvolvimento de novas tecnologias, criação de empresas voltadas ao desenvolvimento tecnológico, financiamento de pesquisas e empresas de base tecnológica, captura de mão de obra qualificada advinda do exterior, dentre outras (Amsden, 2007; Kim; Nelson, 2000).

Uma importante estratégia adotada foi a restrição imposta aos Investimentos Diretos Estrangeiros (IDE). O Estado não permitiu que empresas estrangeiras explorassem a fabricação de produtos que estivessem sendo desenvolvidos pelas empresas nacionais, mas somente que atuassem em campos de não interesse estratégico nacional ou em setores que careciam de maior conhecimento tecnológico (para que pudessem se apropriar de tecnologias mais avançadas). Nos últimos, a importância dessas empresas estrangeiras residia principalmente na mobilidade da mão de obra para empresas nacionais, sendo esses profissionais responsáveis por grande parte do desenvolvimento tecnológico das empresas nacionais (Amsden, 2001).

(5) Em 1952, 56\% da população de Taiwan estava empregada no setor agrícola. Em 1970, esse percentual já havia caído para $36,7 \%$. 
No tocante aos subsídios, foi criado em 1982 o Statute for Encouragement of Investment (SEI) que pelo lado da taxação determinava a isenção fiscal para todos os gastos com P\&D realizados pelas firmas e permitia a depreciação acelerada de equipamentos para utilização na $P \& D$ interna. Não obstante, para obter tais benefícios a firma deveria ter um gasto mínimo em P\&D que se situava entre $0,5 \%$ de $1,5 \%$ das vendas em função de seu setor de atuação. Já em fins dos anos 1980, com o aumento dos gastos em P\&D pelas empresas, foram ampliados os requisitos mínimos como certos padrões de qualidade, proteção ambiental e treinamento de mão de obra, para elegibilidade ao programa de incentivos fiscais, para além dos aspectos de investimento em P\&D (Wade, 1990).

Pelo lado financeiro o governo também ofereceu linhas de crédito especiais para a produção de determinados produtos elegidos como prioritários (quase a metade desses produtos estava ligada ao ramo eletrônico ou de comunicação). Dentre essas linhas, o governo introduziu o chamado Programa de Assistência para Indústrias Estratégicas [Assistance Program for Strategic Industries - APSI] em 1982. Com um orçamento de NT\$20 bilhões este programa fornecia às firmas empréstimos a serem amortizados em 10 anos a uma taxa de juros preferencial de $1,75 \%$, que tinham de ser usados para a compra de máquinas necessárias à produção dos itens selecionados. Observa-se assim, o caráter focalizado das políticas do governo que objetivavam induzir áreas específicas para promoção da competitividade nacional (Hou; Gee, 1993).

O país empreendeu ainda substancial esforço na criação de institutos de pesquisa nacionais que fossem capazes não apenas de importar e desenvolver, mas também difundir tecnologias para pequenas e médias empresas, administradas por diversos ministérios. Em 1959, o governo de Taiwan adotou o chamado Plano Nacional de Desenvolvimento de Longo Prazo da Ciência, onde foram definidos oito campos estratégicos: 1) Energia, 2) Materiais, 3) Informação, 4) Automação, 5) Biotecnologia, 6) Óptica, 7) Controle de hepatite e 8) Tecnologia alimentar (Hou; Gee, 1993).

As principais fontes de novas tecnologias se originavam desses institutos, o que permitia às empresas terem menores gastos com P\&D. Por exemplo, em 1973 foi criado o Instituto de pesquisa Industrial [Industrial Technology Research Institute - ITRI] para o desenvolvimento de hardware para a indústria eletrônica e de informação de Taiwan. Em 1979, foi criado o Instituto para Informação Industrial [Institute for the Information Industry - III) para auxiliar as pequenas e médias empresas e o governo no desenvolvimento de softwares para a introdução da computação em seus projetos, treinamento de profissionais e na promoção do uso de novas tecnologias relacionadas à computação (Dodgson, 2000). 
Como exemplo das estratégias de difusão de tecnologia utilizadas pelo Estado, Mathews e Poon (1995) apontam que uma estratégia perseguida por este instituto centrou-se na coordenação de consórcios com múltiplos parceiros, objetivando promover um network para a criação, transferência e difusão de novas tecnologias entre empresas (nacionais e estrangeiras). Em outro exemplo tem-se a atuação da $\mathrm{ERSO}^{6}$, um dos departamentos do ITRI, que tinha a função de desenvolver novas tecnologias para a indústria eletrônica além de promover sua difusão. Após desenvolver novas tecnologias, seus principais canais de difusão se davam por meio de documentos técnicos, organização de conferências para firmas de eletrônicos de Taiwan, acordos de licenciamento de tecnologia e sua estratégia de difusão mais inovadora, as chamadas spin-off venture companies (Hou e Gee, 1993).

Essa última estratégia residia na atuação de alianças diretas entre o governo e o setor privado para a construção de uma nova empresa, caso a tecnologia desenvolvida tivesse um real potencial de mercado. Nesse aspecto, a tecnologia desenvolvida pela ERSO era transferida ao grupo de engenheiros que as desenvolveu e o governo ainda transferia mais tecnologia estrangeira disponível. O capital para formação dessa spin-off company advinha de quatro fontes, a saber, o próprio governo, investidores domésticos industriais ou não, além de capital estrangeiro, de modo que a empresa criada era tipicamente uma empresa privada, com benefícios reais para todos os envolvidos. Como resultado das políticas de difusão tecnológica por esta via, até 1989 haviam sido criadas 6 spin-off companies.

Dentre essas, Hou e Gee (1993) apontam como exemplo a criação da Taiwan Semiconductor Manufacturing Company (TSMC), uma joint venture criada entre o ITRI e a Philips, constituída para sanar uma lacuna de mercado que residia na ausência de escala das pequenas firmas de Taiwan para produção de Circuitos Integrados (CIs). Isto porque as firmas nacionais eram capazes de realizar os desenhos, mas não tinham escala nem tecnologia suficiente para produzi-los de modo a suprir o mercado adequadamente. Então a TSMC passou a atuar na produção de CIs customizados para as várias firmas que projetavam esses CIs. Assim, somente entre 1987 e 1989, puderam ser criadas quase 50 novas empresas nesse ramo.

A atuação incisiva do governo para o desenvolvimento de background tecnológico nacional também pode ser visto no caso DRAM. Em 1988, a escassez deste componente - Dynamic Random Access Memory (DRAM) - no mercado eletrônico em Taiwan se tornou problemática e havia grande risco na criação de uma planta para sua fabricação para empresas nacionais. Nesse sentido, o governo

(6) Eletronic Research and Service Organization 
Papel do Estado para o desenvolvimento do SNI: lições das economias avançadas...

o colocou em sua lista de produtos de alta tecnologia importantes e forneceu subsidio fiscal para a atuação nesse setor. Assim, um grupo de spin-off companies criadas pela ERSO em conjunto com algumas outras empresas de Taiwan acabaram por formar uma aliança para o desenvolvimento de novas tecnologias DRAM, sob coordenação do ministério de Assuntos econômicos de Taiwan. Foram empregados 200 engenheiros e técnicos, com um plano de investimento de 5 a 6 bilhões, em 5 anos, no projeto para o desenvolvimento da tecnologia de chip 16M DRAM e 8M SRAM (Hou; Gee,1993).

Como resultado, em 1997, Taiwan já competia no mercado DRAM e SDRAM mundial com países como Japão, EUA e alguns países europeus (ICE, 1997). Interessante notar que, até chegar nesse ponto de desenvolvimento tecnológico, de coordenação entre firmas e até mesmo a criação dessas firmas, sem contar com o background educacional fornecido, a participação do governo foi essencial na construção de empresas de base tecnológica em Taiwan.

Outra medida tomada pelo governo foi a construção em 1980 do Hsinchu Science-based Industrial Park, um parque tecnológico com o objetivo de reunir empresas de alta tecnologia, institutos de pesquisa, bem como um grande volume de mão de obra qualificada - em especial aqueles profissionais altamente qualificados que haviam migrado para o exterior por falta de oportunidades no país - para propiciar uma maior competitividade ao país via desenvolvimento de novas tecnologias. Em 1988 já havia 96 empresas de alta tecnologia instaladas com 16.500 profissionais empregados, sendo que de todos estes, $41 \%$ tinham nível superior. As vendas dessas firmas aumentaram de NT\$ 3.3 bilhões em 1983 para NT\$48.3 bilhões em 1988 (Hou; Gee, 1993; Dodgson, 2000).

Não obstante, tais políticas não teriam obtido êxito sem um correspondente aumento da educação fortemente sustentado pelo governo. Em 1952, o país tinha uma taxa de analfabetismo de 42,1\%, em 1970 essa taxa caiu para 14,7\%, em 1988 para $7,4 \%$ e em 2004 para 2,09\%. E a proporção da população com educação superior saltou de 1,4\% em 1952 para 3,7\% em 1970, e para 10,1\% em 1988. Em 2004, 35\% da população possuía nível superior com notada proporção de matriculas em áreas como engenharias e ciências naturais. Os gastos com educação saíram de $10 \%$ dos gastos totais do governo em 1950 para $15 \%$ em 1970 . Houve ainda um foco no ensino superior, sendo que os gastos para este triplicaram entre 1952 e 1980 (Taiwan, 2011; Hou; Gee, 1993).

Ademais, o governo investiu não apenas no ensino superior, como no aumento das chamadas escolas vocacionais que oferecem ensino profissional equivalente ao ensino técnico no Brasil. O número de alunos matriculados em escolas vocacionais saltou de 40.092 em 1952 para 349.138 em 1980 e para 449.111 em 1990, sendo que a partir de 1980, quase 50\% dos alunos estavam 
matriculados em escolas vocacionais ligadas à industria, enquanto que em 1952 a maioria estava alocada em escolas vocacionais agrícolas. (Taiwan, 2011).

No entanto, cumpre salientar que também as políticas educacionais não teriam tido êxito sem o desenvolvimento da competitividade das indústrias. Entre 1950 e 1978, apenas 6.000 estudantes, de 50.000 que deixaram Taiwan para estudar no exterior, retornaram. O setor público passou a oferecer algumas vantagens para trazer de volta esses profissionais, porém não era suficiente para absorver toda a mão de obra qualificada. Nesse sentido, as políticas para o desenvolvimento de novas tecnologias em firmas locais foi fundamental, de modo que o investimento conjunto em fatores e tecnologias focadas em setores específicos potencializaram-se mutuamente. Já no final da década de 1970, a fuga de cérebros passou a ser reduzida acentuadamente (Wade, 1990).

Quanto à estrutura dos gastos entre setor público e privado, os gastos em P\&D de Taiwan eram financiados em sua maioria pelo governo. Em 1986, 60\% dos gastos eram financiados pelo governo, enquanto o setor privado era responsável por $40 \%$ desse montante. No mundo, esse quadro estava se revertendo com maior participação das firmas no financiamento ao $\mathrm{P} \& \mathrm{D}$, porém, Taiwan estava vivendo seu momento histórico de realização de seu catching up e a participação governamental foi de fundamental importância para essa alavancagem, por todas as políticas apresentadas. Já em 1999, com o aumento da robustez do setor empresarial, a estrutura de financiamento já era bem diferenciada com $64,1 \%$ do P\&D financiado pelas firmas e $23,4 \%$ pelo governo e, em 2008 , a proporção era de 70,7\% e 16,8\%, respectivamente (Taiwan, 2011).

Por outro lado, a postura adotada pelo o governo desde 1960, após a promoção da política de substituição de importações, com a adoção de uma política agressiva de exportação, sempre propiciou um ambiente de forte competição para as empresas nacionais, não optando por uma política demasiadamente protecionista, evitando assim que a criação de um ambiente artificialmente produzido pudesse inibir a competitividade das firmas.

Assim, somente a partir da determinação de um esforço de cunho nacional com a estipulação de objetivos e metas, o país pôde promover uma mudança tecnológica e fazer seu catch up. Em 1986, quando país gastava 1,01\% do PIB em P\&D, o governo fixou como meta que esse gasto seria 2\% do PIB em 1995. Efetivamente, em 1995, o país investiu perto de sua meta: 1,78\% do PIB. Já em 2008, o país investiu 2,78\% do PIB chegando perto do Japão, que teve um investimento no período de $3,48 \%$ do PIB em P\&D, demonstrando o comprometimento com o cumprimento das metas nacionais estabelecidas. (Hou; Gee, 1993; Taiwan, 2011). 
Papel do Estado para o desenvolvimento do SNI: lições das economias avançadas...

\subsection{Coreia do Sul}

A Coreia possui um dos regimes de civilização mais antigos do mundo, mantendo-se como Estado independente e unificado por mais de 1.200 anos, o que lhe permitiu formar uma base cultural consolidada. Não obstante, o país sofreu frequentes invasões de grandes potências, sendo sua ultima colonização realizada pelo Japão entre 1910 e 1945. Segundo Kim (1997) e Odagiri (2006), durante esse período teria ocorrido um desmantelamento das estruturas coreanas e o Japão teria inibido o acesso dos coreanos à educação a fim de formar uma massa de trabalhadores com pouco senso crítico. Assim, ao final do domínio japonês, a taxa de analfabetismo era de $78 \%$ no país e somente $2 \%$ da população acima de 14 anos tinha completado o ensino médio. Ademais, os trabalhos técnicos das indústrias, aqueles que exigiam mais conhecimento, permaneceram concentrados na mão dos japoneses - os coreanos representavam apenas $19 \%$ de todos os técnicos do setor industrial - e as empresas estavam concentradas sob o domínio do capital japonês ( $94 \%$ do capital industrial da Coreia).

Conforme afirma Kim (1997), tamanho era o desconhecimento coreano das técnicas industriais japonesas que, ao fim da guerra, com a saída do Japão da Coreia, mesmo os japoneses abandonando muitas plantas industriais no país, os coreanos não sabiam como utilizar aquele maquinário disponível. Na construção naval, por exemplo, os japoneses haviam deixado um estaleiro com quatro navios de pequeno porte ainda em construção. Quando os coreanos conseguiram enfim apreender o conhecimento necessário para terminar os navios semiacabados, eles já estavam tão enferrujados que tiveram de ser sucateados.

Com a saída do Japão após a Segunda Guerra Mundial, o país entrou em um vácuo político e econômico que se somou à divisão arbitrária do país em Coreia do Norte e Coreia do $\mathrm{Sul}^{7}$ em 1945 e à guerra da Coreia - 1950 e 1953 - que, segundo estimativas do governo, destruiu quase metade das instalações industriais no país. Em 1948, a produção industrial da Coreia do Sul caiu para aproximadamente $15 \%$ daquela realizada em 1939. Assim, a Coreia do Sul emergiu da guerra como uma economia baseada na agricultura de subsistência $(47 \%$ do PNB sob responsabilidade da agricultura e silvicultura), com setor industrial desmantelado, nível educacional baixíssimo, fraca capacitação tecnológica e com um setor financeiro praticamente inexistente ${ }^{8}$ (a maioria das instituições financeiras era japonesa). Em suma, o país se encontrava em uma situação calamitosa, o mais pobre entre os países de industrialização recente (Kim, 1997).

(7) Esta promoveu uma substancial divisão da capacidade instalada do país. A Coreia do Sul, por exemplo, manteve cerca de dois terços da população, porém, perdeu mais de $90 \%$ da capacidade de geração de energia elétrica e $75 \%$ da produção de carvão e minério de ferro para a Coreia do Norte.

(8) As trocas eram realizadas, em sua grande maioria, em espécie, quando não por meio de escambo. 
Não obstante, entre 1953 e 1970, o país mudou completamente sua estrutura produtiva. O setor industrial que respondia por 9\% do PIB em 1953 saltou para $18 \%$ em 1965 e para $25,9 \%$ em 1975 , enquanto a participação do setor primário decresceu de $47,3 \%$ do PIB para $24,9 \%$ em 1975. A estrutura do setor industrial também mudou substancialmente: em 1953, a participação da indústria pesada no total da produção industrial foi de $21,1 \%$, saltando para $47,9 \%$ em 1975 e a participação de produtos industrializados nas exportações aumentou de 14,3\% em 1963 para mais de 92\% em 1994 (Kim, 1997).

O Estado foi um agente fundamental para a ocorrência das mudanças. Sem sua presença não é possível explicar o crescimento vertiginoso do país em tão pouco tempo. Na década de 1950 foi iniciada uma forte política de substituição de importações no país, em semelhança ao ocorrido na América Latina e em Taiwan, ensejando a fortificação do setor produtivo nacional que perdurou até 1960. Já em 1961, tomou posse um governo mais centralizado e forte que tomou como objetivo a industrialização do país, tendo permanecido no poder até o inicio da década de 1970. Sob sua orientação foi realizada uma marcha forçada rumo ao desenvolvimento do setor industrial no país (Wade, 1990).

Em 1962 foi lançado o primeiro plano econômico quinquenal com o reconhecimento da importância da C\&T para o desenvolvimento industrial. Nesse sentido, o governo tomou medidas tanto pelo lado da demanda (política industrial) quanto pelo lado da oferta (política científica). Porém, a primeira teve maior peso que a segunda, sendo os chaebols ${ }^{9}$ os motores do rápido crescimento econômico coreano (Lee, 2000).

Pelo lado da oferta, o governo passou a adotar uma política voltada à promoção das exportações aliada à política anterior de substituição de importações. Uma das primeiras medidas tomadas pelo governo foi a coerção para que grupos empresariais investissem em áreas estratégicas dirigidas pelo governo, com clara orientação autoritária ${ }^{10}$. Dado esse pano de fundo, o governo realizou a promoção deliberada das empresas por meio de um conjunto sistemático e abrangente de subsídios e incentivos. Tamanha era a atuação do governo para a promoção dos chaebols que alguns autores chegaram a denominar o governo coreano como uma grande corporação chamada "Coreia S/A", sendo os chaebols suas unidades de produção. O governo fomentava e regia com mãos de ferro os mecanismos que permitiam às empresas alcançar um aprendizado tecnológico rápido (Kim, 1997).

(9) Conglomerados formados por várias empresas em diferentes áreas de negócios, pertencentes a uma ou duas famílias e administrada por seus membros.

(10) Segundo Kim (1997), o governo prendeu 13 empresários acusando-os de enriquecimento ilícito, soltando-os posteriormente sob a coerção de realizarem os planos do governo. 
O governo induzia crises para as que empresas pudessem reagir criativamente às dificuldades, porém ao mesmo tempo fornecia subsídios para auxiliar as mais competitivas a sobreviverem. Um claro indicativo foi $o$ estabelecimento de metas de desempenho de exportação para as empresas, de modo que somente aquelas que conseguissem alcançá-las receberiam determinados subsídios do governo como crédito e tarifas diferenciadas. As empresas orientadas para exportação tiveram que se tornar competitivas internacionalmente e, para tal, necessitaram investir pesadamente em aprendizado tecnológico (Amsden, 1989).

Respondendo adequadamente às metas, o governo canalizava aos vencedores vultosos volumes de empréstimos do exterior, acesso irrestrito e isento de tarifas aos insumos intermediários importados e acesso ilimitado a bens de capital estrangeiros. Ademais, recebiam uma série de isenções tarifárias como taxas de depreciação aceleradas, isenção de impostos sobre valor adicionado e importação de matérias-primas e peças de reposição (Kim, 1993).

Como o governo passou a controlar o sistema bancário, outra medida tomada por este foi o racionamento proposital de crédito com a finalidade de incentivar a diversificação e o contínuo aumento das exportações. Com dificuldade de acesso ao crédito, as empresas eram forçadas a receber divisas de exportação para se manterem em funcionamento. $\mathrm{O}$ crédito bancário também foi usado para punir aquelas empresas que não alcançassem as metas de exportação de seu setor: "Se uma empresa não respondesse a determinadas metas, programas ou incentivos propostos, sua declaração de renda ficava sujeita a cuidadosa avaliação, ou seus pedidos de crédito eram deliberadamente ignorados (...). As agências governamentais não hesitavam em lançar mão de medidas autoritárias, recorrendo inclusive à coerção" (Kim, 1997).

Por meio dessas políticas, o governo obrigou as empresas a investirem pesadamente em aprendizado tecnológico, além de adquirir, assimilar e aperfeiçoar tecnologias estrangeiras a fim de garantirem sua existência. Porém, ao mesmo tempo provia recursos para que as mais competitivas permanecessem no mercado. Com tais medidas, o valor de suas exportações aumentou de 5,8\% do PNB em 1965 para 12\% do PNB em 1971. Durante o mesmo período a Coreia obteve uma taxa de crescimento médio anual de $36 \%$ ao ano, saltando do $101^{\circ}$ lugar entre os países exportadores, para o $14^{\circ}$ lugar em 1986 (Kim, 1993).

O governo autoritário ainda reprimiu severamente os sindicatos, de modo que os trabalhadores coreanos trabalhavam muito mais horas que muitos trabalhadores ocidentais, assim como tinham um número de faltas bem abaixo da média mundial e férias também reduzidas ${ }^{11}$. Como resultado, havia uma força de trabalho extremamente submissa, com alta produtividade e recebendo baixos

(11) Meio dia de faltas em média por ano, contra 50 dias verificados no EUA. 
salários. Por outro lado, o governo também buscou selecionar jovens capacitados para a administração pública, objetivando alcançar mais eficiência nas ações do governo, o que permitiu um monitoramento bem próximo do governo do desempenho das empresas (Kim, 1997).

Pelo lado da oferta - política científica - o papel do governo durante as décadas de 1960 e 1970 esteve vinculado à criação de institutos públicos de pesquisa e universidades, bem como à promoção das empresas estatais. Em 1966 foi criado o Korea Institute of Science and tecnology, o primeiro centro técnico moderno e integrado do país. Em 1971 foi fundado o Instituto de Estudos Avançados da Coreia do Sul oferecendo cursos de mestrado e doutorado de alta qualidade e muitas instituições de pesquisa governamentais foram fundadas durante toda a década de 1970 (Lee, 2000).

Porém, o papel do Estado não foi muito decisivo nas primeiras décadas do desenvolvimento por estes mecanismos. Isso porque, com a necessidade de aumentar suas exportações, as empresas precisavam se focar na aprendizagem tecnológica para competir no mercado mundial e logo passaram a buscar estratégias de engenharia reversa, atuando primeiramente de modo imitativo. E os institutos de pesquisa ${ }^{12}$ criados pelo governo não podiam oferecer às empresas os protótipos industriais necessários à criação produtiva (Kim, 1997).

Os incentivos governamentais ao estabelecimento de laboratórios de $\mathrm{P} \& \mathrm{D}$ dentro das empresas também se mostraram infrutíferos pelos mesmos motivos. Já as empresas estatais se mostraram mais atuantes por meio da transferência de engenheiros - que tiveram acesso a tecnologias de ponta em modernas empresas estatais - e máquinas para o setor privado. Somente na década de 1980 esses esforços foram mais bem aproveitados. Houve, nesse período, uma considerável mudança no ambiente econômico, os fluxos internacionais de tecnologia se tornaram mais restritos ${ }^{13}$ e houve aumento da complexidade das novas tecnologias. A capacidade instalada pretérita de pesquisa permitiu que na década de 1980 fossem criados programas colaborativos entre o governo e os chaebols, objetivando o desenvolvimento de novas tecnologias (Wade, 1990).

Neste período, o Estado também aumentou seus investimentos em P\&D. Em 1982, o governo criou o programa denominado $P \& D$ Designado para financiamento de pesquisas em alta tecnologia e em 1987 criou o chamado Programa de Desenvolvimento de Tecnologia Industrial para financiar até dois terços dos programas de pesquisa colaborativos. Até 1993, os dois programas

(12) Eram os principais responsáveis pela produção de pesquisa, uma vez que as universidades sempre estiveram muito voltadas ao ensino na Coreia.

(13) O Japão foi um dos primeiros países a impedir que suas tecnologias fossem transferidas à Coreia quando observou que esta estava competindo com seus produtos. 
Papel do Estado para o desenvolvimento do SNI: lições das economias avançadas...

gastaram US\$ 3,1 bilhões em 3.838 projetos, sendo que somente para o primeiro projeto foram empregados cerca de 25 mil pesquisadores e foram gerados 1.384 pedidos de patentes. Já em 1994, foi criado o projeto $H A N$ para amparar o desenvolvimento de projetos de alta tecnologia de importância estratégica definida pelo Estado. O diferencial desse programa foi que as empresas forneciam uma parcela dos recursos para a realização das pesquisas e em troca podiam reivindicar os direitos sobre seus resultados. Em dois anos foram selecionados 11 projetos que geraram 1.634 pedidos de patentes (Kim, 1997; Lee, 2000).

O governo também passou a adotar programas de incentivo à criação de laboratórios formais de P\&D no setor privado, como incentivos fiscais e financiamentos especiais para sua instalação e dispensa do serviço militar para profissionais diretamente ligados às atividades de $\mathrm{P} \& \mathrm{D}$. Como resultado desses incentivos e da mudança do ambiente econômico, o número de laboratórios em empresas privadas saltou de 1(um) em 1970 para 2.272 em 1995 (Kim, 1997).

No tocante à formação da mão de obra, o governo também atuou diretamente aumentando a parcela do orçamento público destinada à educação de $2 \%$ em 1950 do PIB para mais de 17\% em 1966. Porém, sua participação foi apenas dois terços daquela investida pelo setor privado. Com o fim da ocupação japonesa na Coreia e a possibilidade dos cidadãos poderem estudar, houve uma demanda crescente por educação no país que emergia dos próprios cidadãos ${ }^{14}$, de modo que no curto prazo houve inclusive um pequeno descompasso entre a formação de mão de obra e a oferta de empregos. Porém, com as políticas de promoção deliberada aos chaebols, em pouco tempo houve um reequilíbrio no mercado de trabalho, pois logo as empresas passaram a demandar mais mão de obra qualificada (Kim, 1997; Lee, 2000).

Nesse sentido, o governo também passou a incentivar a construção de escolas de formação técnica dentro das empresas. Em 1974, promulgou uma lei que tornou obrigatório o ensino profissionalizante nas empresas com mais de 300 empregados. Com esta medida, o número de alunos formados pelas escolas empresariais mais que triplicou entre 1970 e 1980, saltando de 31.621 em 1970 para $104.504 \mathrm{em} 1980$ (Kim, 1997).

Sobre a formação de nível superior, ainda que a participação direta do governo não tenha sido tão incisiva (havia maior participação do ensino superior privado), a política de promoção dos chaebols foi diretamente decisiva na orientação da formação dos alunos, uma vez que estes passaram a demandar profissionais mais ligados às engenharias e ciências. Como consequência, em vinte anos, entre 1960 e 1980, o número de engenheiros foi multiplicado por 10 no país,

(14) Nesse sentido, Kim (1997) destaca o importante papel da filosofia confucionista de valorização do aprendizado entre os coreanos. 
sendo que esses profissionais tiveram um papel fundamental no aprendizado tecnológico imitativo (Wade, 1990).

Com relação à aquisição de tecnologia estrangeira, o governo adotou fortes políticas de restrição ao IDE e ao licenciamento de tecnologia estrangeira durante a década de 1970 em setores estratégicos, buscando aprofundar o aprendizado tecnológico por outros mecanismos. O índice de participação estrangeira nas empresas foi limitado a $50 \%$. Havia requisitos de exportação às empresas estrangeiras, limites ao licenciamento de tecnologias e a concorrência de empresas estrangeiras com empresas nacionais raramente era permitida. Tais medidas buscaram fortalecer a competitividade das firmas nacionais, o que propiciou uma significativa independência administrativa das empresas coreanas em relação às multinacionais, bem como o fortalecimento do poder de negociação das empresas coreanas para a transferência de tecnologias maduras (Kim, 1993).

Somente quando as empresas nacionais passaram a internalizar conhecimento tecnológico e quando o acesso às tecnologias estrangeiras passou a se tornar mais difícil, em meados da década de 1980, o governo passou a afrouxar sua política em relação ao IDE e ao licenciamento de tecnologias. Nesse ponto, porém, a maioria das empresas já possuía conhecimento tecnológico suficiente tanto para obter licenciamentos mais vantajosos como para, inclusive, atuar em acordos estrangeiros de desenvolvimento conjunto de novas tecnologias em alguns setores (Amsden, 1989).

Em estágios tecnológicos mais maduros, os chaebols, passaram a adotar outras medidas mais agressivas desde a instalação de filiais em países desenvolvidos para captação de tecnologias emergentes e compra de ações de empresas estrangeiras tecnologicamente avançadas, até a realização de pesquisas colaborativas com grupos estrangeiros de alto porte tecnológico e instalação de laboratórios de P\&D em parques tecnológicos de países desenvolvidos, como o Vale do Silício ${ }^{15}$. São exemplos de realizações desses tipos, (i) o investimento da Samsung na AST para produção de computadores pessoais, (ii) a compra da Zenith pela LG para produção de televisores de alta definição e acesso a patentes, e (iii) as associações de chaebols com empresas como Apple, Intel, Microsoft e Toshiba, para o estabelecimento de alianças estratégicas para o desenvolvimento de novas tecnologias (Kim, 1997).

\section{Considerações finais}

A partir da apresentação resumida da atuação do Estado para os países selecionados, verifica-se que tanto os países desenvolvidos quanto os em desenvolvimento utilizaram o Estado como importante ator para o alcance de uma

(15) Hyundai, Samsung e LG são exemplos de empresas que instalaram laboratórios no Vale do Silício. 
trajetória tecnológica superior. A participação ativa do governo para promoção do avanço tecnológico pôde ser observada na indução da competitividade empresarial, nas medidas de atuação direta de financiamento, na coerção (como no caso da Coreia), na criação de empresas públicas nos momentos iniciais de industrialização para assumir riscos em setores que o setor privado não está disposto a assumir ou capacitado a financiar, na oferta de uma ampla base educacional, na construção de laboratórios de pesquisa e universidades para a formação de profissionais qualificados de nível superior e/ou desenvolvimento de pesquisas/radares de tecnologia externa, na oferta de incentivos fiscais e cambiais, e na regulação e institucionalização da inovação.

Não obstante, a atuação do Estado muda em função dos diferentes momentos históricos, econômicos e características políticas e sociais de cada nação. Para países de industrialização recente, a participação do Estado foi mais incisiva para a mudança da matriz produtiva, com medidas e ações ao mesmo tempo pontuais e universais, tendo que agir em diferentes frentes de atraso. Já para os países que se industrializaram até o início do século XX, a atuação do Estado apesar de forte, foi executada de um modo um pouco distinto, pois estes já dispunham de alguma base para sua construção, como a presença de grupos empresariais com relativa autonomia, base educacional construída, etc.; enquanto os primeiros tiveram que fazer sua construção praticamente a partir de um vácuo.

A partir da análise das medidas governamentais de promoção dos SNIs desses países verifica-se uma participação decisiva do Estado em termos de políticas para indução de habilidades e competências nacionais. É certo que esta análise não nos permite inferir que políticas semelhantes terão os mesmos efeitos se tomadas agora por economias menos desenvolvidas, pois as características específicas de cada ambiente nacional e de cada período histórico influenciam tanto sobre as modalidades de políticas que podem ser implementadas, quanto sobre resultados que podem ser esperados (Freeman, 1982; Lundvall, 1992). Este estudo não objetivou apontar medidas de caráter determinístico nesse sentido.

Todavia, existem certos traços comuns a estas políticas que, independentemente do período, nação ou modo como foram executadas, propiciaram vantagens e permitiram um desenvolvimento dos SNIs analisados. Desde o ensino básico ao técnico, superior e de pós-graduação, avanços nos sistemas educacionais foram requisitos básicos para o alcançamento de estágios superiores de desenvolvimento tecnológico. De forma semelhante, a importação de tecnologia estrangeira, imitação e engenharia reversa, investimentos governamentais em $\mathrm{P} \& \mathrm{D}$, criação de laboratórios de pesquisa, incentivos fiscais e subsídios para contratação de mão de obra especializada e importação de maquinas também foram medidas que se mostraram relevantes para o processo de catching up tecnológico nas economias analisadas. 
A coordenação destas ações, porém, foi o aspecto que mais demandou atenção do Estado para a promoção destas políticas. Em todos os casos é possível observar a presença implícita (e explícita) de um plano de atuação governamental bem delineado. A consciência da realidade de suas economias e das características externas que os cercavam permitiu o desenho de políticas adequadas, porém, construídas em torno de um objetivo nacional. Somente com o conhecimento de cada realidade foi possível a construção de políticas adequadas ao fortalecimento de cada SNIs.

Outro aspecto a ser considerado são os diferentes paradigmas tecnoeconômicos em que os países realizaram seu catch up. Conforme salienta Perez (2002), a cada revolução tecnológica, inicia-se um novo paradigma tecnoeconômico onde se abrem janelas de oportunidade que permitem o ingresso de novos atores no cenário tecnológico e econômico mundial, em bases mais competitivas, por meio da maior instabilidade do novo conjunto de tecnologias nascentes. Tal fato pode ser observado no caso alemão e americano, cujo ingresso dá da mudança da segunda para a terceira revolução tecnológica. O ingresso do Japão, por sua vez, ocorre na transição da terceira para a quarta revolução tecnológica, e Taiwan e Coreia, da quarta para a quinta.

Contudo, a cada novo paradigma tornam-se maiores os requerimentos mínimos para a admissão neste. Os esforços requeridos pelo Japão foram maiores do que aqueles necessários para os EUA e Alemanha, enquanto para os países de industrialização recente foram ainda mais intensos. Tal fato ocorre em virtude da continuidade do movimento das demais economias, de modo que se Taiwan e Coreia realizassem os mesmos esforços já empreendidos pelas economias mais avançadas e em seu mesmo ritmo, apenas ficariam no mesmo lugar. Para superar a posição de atraso em paradigmas tecnoeconômicos mais recentes são necessários esforços superiores àqueles já desenvolvidos pelas economias que já realizaram o catch up.

Deste modo, poderia ser inferido que quanto mais distante determinada nação se encontra da fronteira tecnológica do paradigma tecnoeconômico em vigência, maiores são as necessidades de atuação do Estado para promoção de medidas estratégicas coordenadas para o fortalecimento de seu SNI. Isto porque haveria a necessidade de um conjunto mais intenso de estratégias coordenadas para a superação de várias frentes de atraso. Por outro lado, Amsden (2001) aponta que talvez a intervenção do governo não seja maior quando a industrialização é mais tardia, mas apenas um pouco diferente. Ou seja, embora a velocidade e modalidades de atuação possam ser diferenciadas em função do paradigma tecnoeconômico de realização do catch up de cada nação, o conjunto básico ou o núcleo duro de atuação não teria se alterado entre estas. 
Em suma, observa-se em todas as economias analisadas que não existe uma neutralidade estatal para a construção de estratégias competitivas em termos políticos, econômicos ou financeiros. Uma forte orientação governamental voltada a este objetivo, aliada a um comprometimento no cumprimento das metas estipuladas, e a presença de um ambiente econômico mundial favorável podem ter impactos significativos para o progresso das nações, que não pode ser deixado apenas a cargo do mercado. Finalizamos, então, com as palavras de Freeman (1984, p.16) sobre essa importância do papel do governo. Como destaca o autor, urge a necessidade de estimular a elaboração de políticas públicas fortes e pacientes para o apoio à ciência fundamental, à tecnologia fundamental, e à inovação radical, o que reclama por uma política governamental decidida.

\section{Bibliografia}

ALBUQUERQUE, Eduardo da Motta. Catching up no século XXI: construção combinada de sistemas de inovação e de bem-estar social. In: SICSÚ, João; MIRANDA Pedro (Ed.). Crescimento econômico: estratégias e instituições. Rio de Janeiro: Ipea, 2009.

BANCO MUNDIAL. World Bank Indicators. Disponível em: http://data.worldbank.org/indicator/.

AMSDEN, Alice. Asia's next giant: South Korea and late industrialization. New York: Oxford University Press, 1989.

[2004]. A ascensão do resto: os desafios ao ocidente de economias com industrialização tardia. São Paulo: Editora Unesp, 2001.

Escape from empire: the developing world's journey through heaven and hell. Cambridge, Mass.: The MIT Press, 2007.

CAHAN, David. The institutional revolution in German physics, 1865-1914. Historical Studies in the Physical Sciences, v. 15, n. 2, p. 1-65, 1985.

ICE. Memory 1997: complete covarege of DRAM, SRAM, EPRON and FLasch Memory ICs. Scottsdale: ICE, 1997.

DODGSON. As políticas para ciência, tecnologia e inovação nas economias asiáticas de industrialização recente. In: KIM, Linsu; NELSON, Richard (Ed.). Tecnologia aprendizado e inovação: as experiências das economias de industrialização recente. Campinas: Editora Unicamp, 2000.

ERGAS, Henry. The importance of technology policy. In: DASGPUTA, Partha; STONEMAN, Paul (Ed.). Economic policy and technological performance. Cambridge; New York: Cambridge University Press, 1987.

FREEMAN, Chris [1982]. Technological infrastructure and international competitiveness, The First Globelics Conference 'Innovation Systems and Development Strategies for the Third Millennium', Rio de Janeiro, November 2-6, 2003. 
FREEMAN, Chris. Inovação e ciclos longos de desenvolvimento econômico. Ensaios FEE, , v. 5, n. 1 p. 5-20, 1984.

. Technology policy and economic performance: lessons from Japan. London: Pinter Publishers, 1987.

. The nature of innovation and the evolution of the productive system. In: TECHNOLOGY and productivity: the challenge for economic policy. Paris: OECD, 1991.

GUIMARÃES, Alexandre Queiroz. O capitalismo coordenado alemão: do boom do pósguerra à agenda 2010. Lua Nova, 66, p. 23-56, 2006.

HARAYAMA, Yuko. Japanese technology policy: history and a new perspective. Research Institute of Economy, Trade and Industry, 2001. (RIETI Discussion Paper Series, 01-E-001).

HOU, Chi-Ming; GEE, San. National systems supporting technical advance in industry: the case of Taiwan. In: NELSON, Richard (Ed.). National innovation systems: a comparative analysis. New York: Oxford University Press, 1993.

KECK, Otto. The national system for technical innovation in Germany. In: NELSON, Richard (Ed). National innovation systems: a comparative analysis. New York: Oxford University Press, 1993.

KIM, Linsu. National system of industrial innovation: dynamics of capability building in Korea. In: NELSON, Richard (Ed). National Innovation Systems: a comparative analysis. New York: Oxford University Press, 1993.

. [2005]. Da imitação à inovação: a dinâmica do aprendizado tecnológico da Coreia. Campinas: Editora Unicamp, 1997.

; NELSON, Richard (Ed.). [2005]. Tecnologia aprendizado e inovação: as experiências das economias de industrialização recente. Campinas: Editora Unicamp, 2000 .

LALL, Sanjaya [2005]. A mudança tecnológica e a industrialização nas economias de industrialização recente da Ásia: conquistas e desafios. In: KIM, Linsu; NELSON, Richard.(Ed.). Tecnologia aprendizado e inovação: as experiências das economias de industrialização recente. Campinas: Editora Unicamp, 2000.

LANDES, David. The unbound Prometheus: technological and industrial development in Western Europe from 1750 to the present. Cambridge: Cambridge University Press, 1969.

LEE, Kong Rae [2005]. O aprendizado tecnológico e o ingreso das empresas usuárias de bens de capital na Coreia do Sul. In: KIM, Linsu; NELSON, Richard (Ed.). Tecnologia aprendizado e inovação: as experiências das economias de industrialização recente. Campinas: Editora Unicamp, 2000.

LEE, Yong S. Technology transfer and economic development: a framework for policy analysis. In: LEE, Young S. (Ed). Technology transfer and public policy. London: Quorum Books, 1997. 
LUNDVALL, Bengt-Ake. National systems of innovation: towards a theory of innovation and interactive learning. London: Pinter Publishers, 1992.

; JOSEPH, K. J.; CHAMINADE, Cristina; VANG, Jan. Innovation system research and developing countries. In: LUNDVALL, Bengt-Ake; JOSEPH, K. J.; CHAMINADE, Cristina; VANG, Jan (Ed.). Handbook of innovation systems and developing countries building domestic capabilities in a global setting. Massachusetts; Cheltenham: Edward Elgar Publishing Limited, 2009.

MCT. Indicadores nacionais de ciência e tecnologia. 2011. Disponível em: www.mct.gov.br.

MATESCO, Virene; HANSENCLEVER, Lia. Indicadores de esforço tecnológico: comparações e implicações. Pesquisa e Planejamento Econômico, Rio de Janeiro, v. 6, n. 3, p. 457-482, 1996.

MATHEWS, J. A.; POON, T. S. Innovation alliances in Taiwan: the case of the New PC consortium. Industry in Free China, v. 84, n. 6, 1995.

MOWERY, David; ROSENBERG, Nathan. The U.S. national innovation system. In: NELSON, Richard (Ed.). National innovation systems: a comparative analysis. New York: Oxford University Press, 1993.

[2005]. Trajetórias da inovação: a mudança tecnológica nos Estados Unidos da América no século XX. Campinas: Editora Unicamp, 1998.

NARIN, Francis; HAMILTON, Kimberly S.; OLIVASTRO, Dominic. The increasing linkage between U.S. technology and public science. Research Policy, v. 26, n. 3, p. $317-$ $330,1997$.

NELSON, Richard [2006]. As fontes do crescimento econômico. São Paulo: Editora Unicamp, 1996.

; ROSENBERG, Nathan. Technical innovation and national systems. In: NELSON, R. (Ed.). National innovation systems: a comparative analysis. New York: Oxford University Press, 1993.

ODAGIRI, Hiroyuki; GOTO, Akira. The Japanese system of innovation: past, present, and future. In: NELSON, R. (Ed.). National innovation systems: a comparative analysis. New York: Oxford University Press, 1993 Technology and industrial development in Japan. Oxford: Oxford University Press, 1996.

Advance of science-based industries and the changing innovation system of Japan. In: LUNDVALL, Bengt-Åke; Intarakumnerd, PATARAPONG INTARAKUMNERD; Vang, Jan (Ed.) Asia's innovation systems in transition. Cheltenham and Northampton: Edward Elgar Publishing Limited, 2006.

OHKAWA, Kazushi; KOHAMA, Hirohisa. Lectures on developing economies: Japan's experience and its relevance. Tokyo: University of Tokyo Press, 1989. 
PEREZ, Carlota. Technological revolutions and financial capital: the dynamic of bubbles and golden ages. Cheltenham; Northampton: Edward Elgar Publishing Limited, 2002.

SANTOS, Ester Carneiro do Couto. Fluxos internacionais de tecnologia e a divisão internacional do trabalho: uma abordagem evolucionária. 2014. Tese (Doutorado em Economia)-Centro de Desenvolvimento e Planejamento Regional, Universidade Federal de Minas Gerais, Belo Horizonte, 2014.

SOLOW, Robert M. Technical change and the aggregate production function. Review of Economics and Statistics, v. 39, n. 3, p. 312-320, 1957.

TAIWAN. Taiwan Statistical Databook 2011. Council for Economic Planning and Development. 2011. Disponível em: www.cepd.gov.tw.

WADE, Robert. Governing the market: economy theory and the role of government in East Asian industrialization. Princeton; New Jersey: Princeton University Press, 1990. 